\title{
HIGH ORIGIN OF SUPERFICIAL ULNAR ARTERY AND ITS CLINICAL IMPLICATIONS: A CASE REPORT
}

\author{
K. P. S. Adinarayana ${ }^{1}$, Teki Surekha ${ }^{2}$
}

\section{HOW TO CITE THIS ARTICLE:}

K. P. S. Adinarayana, Teki Surekha. "High Origin of Superficial Ulnar Artery and its Clinical Implications: A Case Report". Journal of Evolution of Medical and Dental Sciences 2015; Vol. 4, Issue 10, February 02;

Page: 1727-1731, DOI: 10.14260/jemds/2015/247

ABSTRACT: Anomalies of upper limb arteries have got clinical implications for nursing staff, surgeons and medical practitioners. Here we have found superficial ulnar artery arising from brachial artery in the middle $1 / 3^{\text {rd }}$ of the arm in the Right upper limb. This anomaly was found during routine dissection in the Anatomy Department, Andhra Medical College. Its frequency varies from $0.7 \%$ to 7\%. Its clinical significance is discussed.

KEYWORDS: Brachial artery, Superficial Ulnar artery (SUA), Radial artery, Common Interosseous artery, Median cubital vein.

INTRODUCTION: Ulnar artery is the larger terminal branch of brachial artery in the cubital fossa ${ }^{1}$. It passes downwards, medially and leaves the cubital fossa deep to the ulnar head of pronator teres which separates the artery from the median nerve. ${ }^{2}$

In the present case the ulnar artery is taking origin from the brachial artery in the middle third of the arm and is running a superficial course. It is passing superficial to the bicipital aponeurosis in the cubital fossa and subjacent to the median cubital vein. It is then passing just lateral to the medial epicondyle of humerus and running superficial to the common flexor origin. Hence it has been named as Superficial Ulnar artery (SUA).

CASE REPORT: During routine dissection for the under-graduate students we have come across this anomaly. In the Right upper limb we have noticed that the superficial ulnar artery (SUA) has taken origin from the middle third of the brachial artery in the arm at a distance of $12.3 \mathrm{cms}$ from the acromian process of scapula. (Photograph 1)

At its origin in the Arm: The SUA along with its venae comitantes is lying lateral to the median nerve. The later on it is crossing to the medial side and comes to lie subjacent to the median nerve. There after it ran a superficial course in the arm, passes just lateral to the medial epicondyle of humerus and superficial to the common flexor origin to enter the cubital fossa.

In the cubital Fossa: The SUA is present superficial to the bicipital aponeurosis and subjacent to the median cubital vein where it is most vulnerable to injury while attempting for intra- venous injections and cannulations.

In the Forearm: The SUA passed superficial to the flexor muscles of the forearm. It passed superficial to the pronator teres muscle and then ran downwards and medially to run lateral to the ulnar nerve. Both the SUA and ulnar nerve are present lateral to the flexor carpi ulnaris muscle. The SUA has not given any significant branches throughout its course in the arm and the forearm. 


\section{CASE REPORT}

At the Wrist: The SUA passed superficial to the flexor retinaculam just lateral to the pisiform bone.

In the Palm: The SUA has ended its course in the palm by formation of the superficial palmar arch which has been completed by the radial artery as usual.

Photograph 1: Showing origin of SUA from the middle third of the brachial artery (Right upper limb).

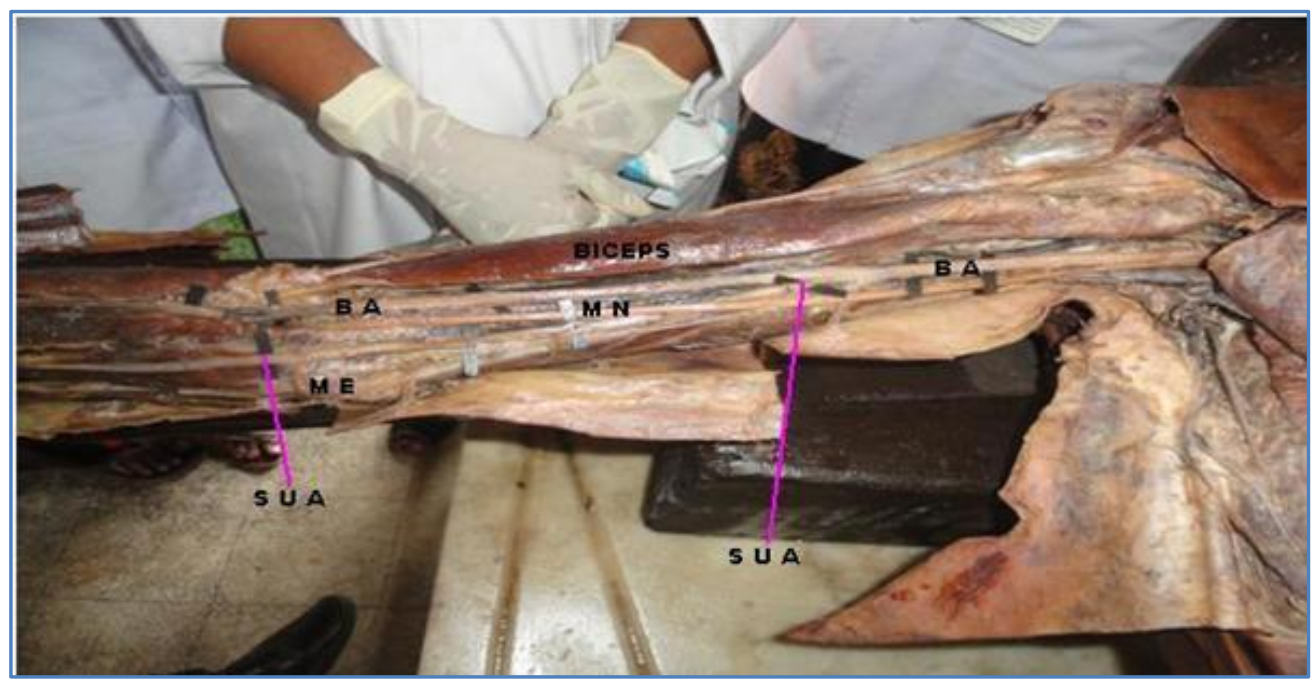

\section{Photograph 1}

BA-Brachial Artery, ME-Medial Epicondyle, SUA-Superficial Ulnar Artery, MN- Median Nerve.

Photograph 2: Showing the brachial artery diving into radial and common interosseous artery in the cubital fossa (right upper limb).

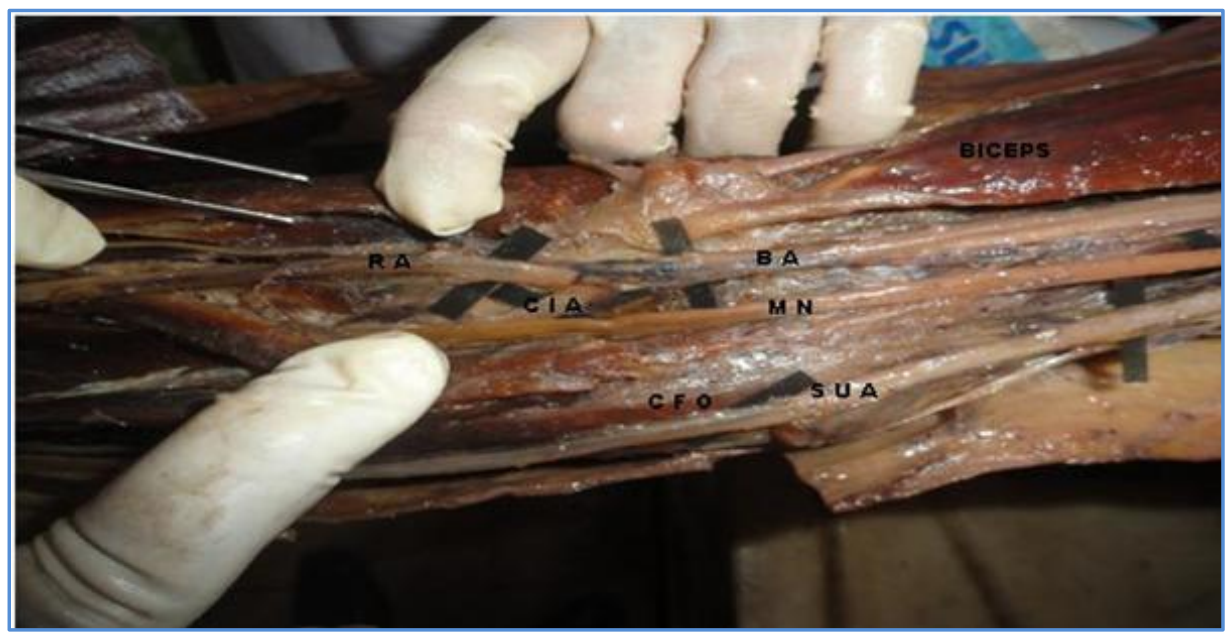

Photograph 2

BA - Brachial Artery, SUA - Superficial Ulnar Artery, MN - Median Nerve, RA - Radial Artery, CIA - Common Interosseous Artery, CFO - Common Flexor Origin. 


\section{CASE REPORT}

In the present case the brachial artery has divided into radial artery and common interosseous artery (instead of ulnar artery) in the cubital fossa at the level of neck of radius (Photograph 2). The common interosseous artery after origin passed deep to the pronator teres muscle and gave muscular branches to pronator teres and other deep muscles of forearm (Photograph 3). After giving muscular branches in the flexor compartment it is running deep and gave a branch which is piercing the interosseous membrane. So, in the present case the muscles of forearm are being supplied by the common interosseous artery instead of ulnar artery.

Photograph 3: Showing the branches of common interosseous artery in the forearm (Right upper limb).

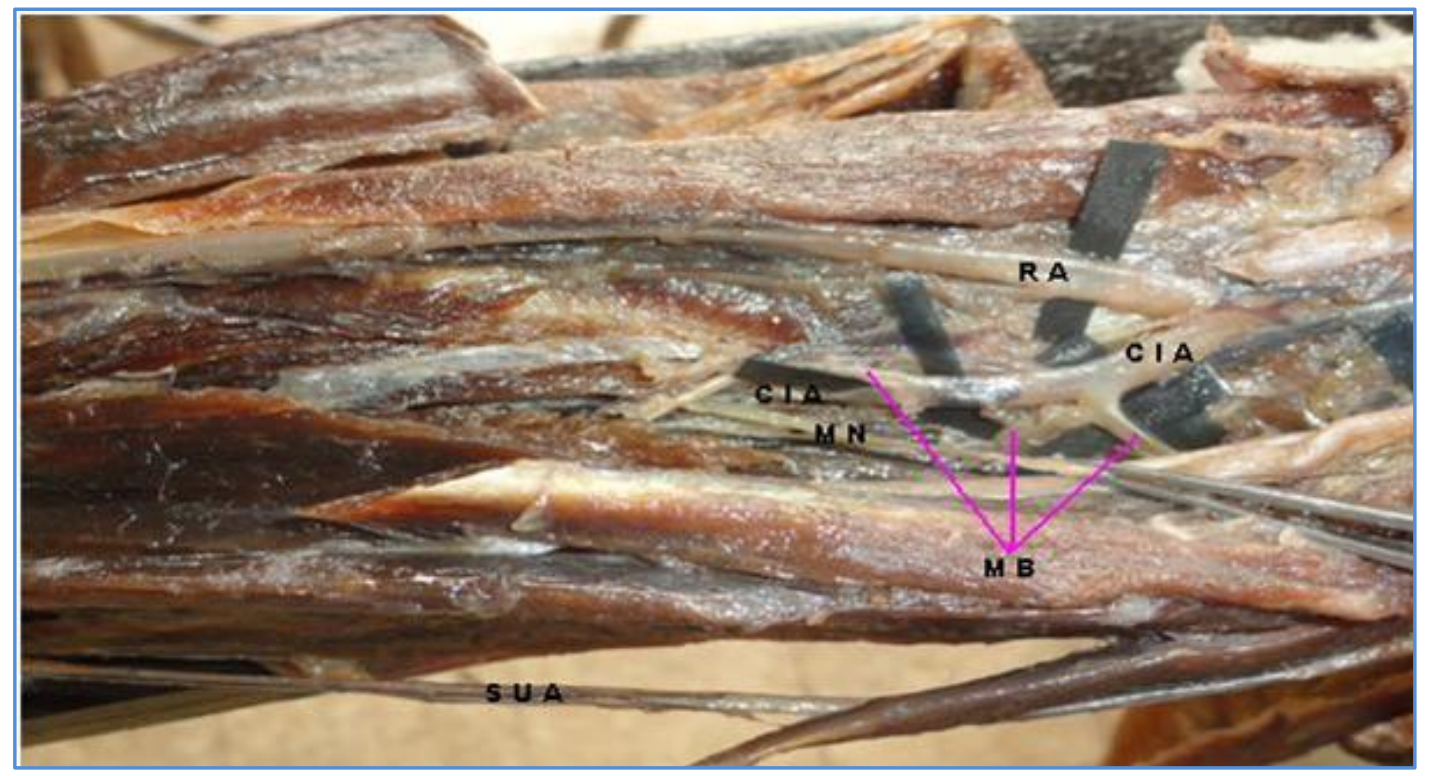

Photograph 3

\section{SUA-Superficial Ulnar Artery, MN-Median Nerve, RA-Radial Artery, MB-Muscular Branches, CIA - Common Interosseous Artery.}

On the left side there is no such variation. The brachial artery has divided into the radial and ulnar artery in the cubital fossa which ran a normal course.

DISCUSSION: Variations of upper limb arterial supply are identified in previous literatures. Presence of abnormal origin of SUA is associated with clinical implications during intravenous injection of drugs and subsequent amputations.,3 The incidence of origin of SUA from axillary artery and brachial artery was reported previously as like this (Table 1 ).

The incidence of SUA was reported to be $0.7-7 \%$ in the literature.5,6,7 In the present case the incidence is $2 \%$ ( 1 case reported out of 50 ). The ulnar artery in the previous publications have been shown to arise frequently from the lower end of the brachial artery. ${ }^{8}$ In cases of high origin the ulnar artery descends over the muscles arising from the medial epicondyle deep to the deep fascia. ${ }^{5}$ The same is observed in the present case. In few cases SUA was reported bilaterally and more often seen in females. ${ }^{5}$ In the present case the SUA is unilateral (Present only on right side). 


\begin{tabular}{|l|c|c|c|c|c|c|}
\hline $\begin{array}{c}\text { Previous } \\
\text { Study: }\end{array}$ & $\begin{array}{c}\text { No. } \\
\text { of } \\
\text { cases }\end{array}$ & $\begin{array}{c}\text { Axillary } \\
\text { artery } \\
\text { (AA) }\end{array}$ & $\begin{array}{c}\text { Brachial } \\
\text { artery } \\
\text { (BA) }\end{array}$ & $\begin{array}{c}\text { Upper } \\
\mathbf{1 / 3} \text { rd } \\
\text { of BA }\end{array}$ & $\begin{array}{c}\text { Middle } \\
\mathbf{1 / 3} \text { (rd } \text { of } \\
\text { BA }\end{array}$ & $\begin{array}{c}\text { Lower } \\
\mathbf{1 / 3} \text { rd of } \\
\text { BA }\end{array}$ \\
\hline Quain(1844) & 31 & 8 & 23 & 6 & 1 & 16 \\
\hline Gruber(1867) & 20 & 4 & 16 & - & - & - \\
\hline Preme(1899) & 7 & 1 & 6 & 1 & - & 5 \\
\hline Muller(1903) & 2 & 1 & 1 & - & - & 1 \\
\hline Mc.Cormack (1953) & 17 & 7 & 10 & - & - & - \\
\hline FuB et al (1985) & 3 & 2 & 2 & - & 1 & 1 \\
\hline Rpdriguez-Baeza(1995) & 8 & 2 & 6 & 3 & 2 & 1 \\
\hline Rodriguez M(2000) & 16 & 4 & 12 & 6 & 3 & 3 \\
\hline Present study(2015) & 1 & - & 1 & - & 1 & - \\
\hline
\end{tabular}

EMBRYOLOGICAL EXPLANATION: Developmentally, the seventh cervical inter segmental branch enlarges and becomes consolidated as the main artery (axis artery) to the developing upper limb bud. This axis artery gives rise to the subclavian, axillary, brachial, and inter osseous arteries. ${ }^{9}$ Other arteries of the upper limb develop as sprouts of the axis artery.

The developmental reason for the superficial ulnar artery in the present case may be due to the ulnar artery establishing a connection with the axis artery in the arm and the bifurcation of the brachial artery into the radial artery and common interosseous artery may be due to the posterior interosseous artery arising from the axis artery just distal to the connection of the radial artery with the axis artery in the cubital fossa region and the continuation of the main trunk (Axis artery) between the radial and posterior interosseous arteries being the common interosseous artery. ${ }^{10}$

\section{CLINICAL IMPLICATIONS:}

1) In the present case the SUA was lying immediately below the median cubital vein. This would predispose the vessel to inadvertent penetration during attempts for venepuncture, i.v. injections and cannulations of the median cubital vein.

2) While treating a case of rupture of the distal bicipital tendon, an orthopaedic surgeon should be aware of such an anatomical variation.

3) The knowledge of this SUA is also required in patients who require surgical intervention because of a thrombosed forearm artery.

4) The presence of SUA is considered as a positive feature for the plastic surgeons to use it in reconstructive ulnar flap.

CONCLUSION: Anomalies of ulnar artery were reported in literature but origin of SUA from middle third of brachial artery is of low incidence. Identification of the ulnar artery variation is of immense clinical significance for surgeons, orthopaedicians, clinicians and para-medical staff. In venous puncture abnormal SUA near to the median cubital vein may be punctured accidentally. Accidental injection of i.v. anaesthetics and drugs may lead to gangrene and subsequent complications. Hence thorough arterial knowledge of upper limb arteries is essential for doctors and paramedical staff. 


\section{REFERENCES:}

1. A. K. Dutta, Essentials of Human Anatomy, Superior and Inferior Extremities, Part III, $4^{\text {th }}$ Edition; May 2009; Current Books International, Kolkata; Chapter -9, Pg no. 66.

2. Henry Gray, Editor in chief- Susan Standring; Gray's Anatomy-The Anatomical Basis of Clinical Practice, 40 th edition; 2008, Reprint 2013; Churchill Livingstone Elsevier publishers; Chapter 48, Pg No. 827, 835, 905.

3. Ohana E, Sheiner E, Gurman GM: Accidental intra-arterial injection of propofol. Eur J Anesthesiol1999, 16:569-570.

4. Goldberg I, Bahar A, Yosipovitch Z: Gangrene of upper extremity following intra-arterial injection of drugs. A case report and review of the literature. Clin Orthop Relat Res 1984, 188:223-9.

5. Rodriguez-Niedenfuhr M, Vazquez T, Nearn L, Ferreira B, Parkin I, Sanudo JR: Variation of the arterial pattern of the upper limbrevisited. J Anat2001, 199:547-566

6. D'costa S, Shenoy BM, Narayana K: The incidence of superficial arterial pattern in the human upper limb extremities. Folia Morphol (Warsz) 2004, 63(4):459-63.

7. Chin KJ, Sing K: The superficial ulnar artery- a potential hazard in patients with difficult venous access. Br J Anaesth2005, 94(5):692-693.

8. Panicker JB, Thilakan A, Chandi G: Ulnar artery: A case report of unusual origin and course. J AnatSoc India 2003, 52(2):177-179.

9. Asim Kumar Dutta - Essentials of Human Embrology $6^{\text {Th }}$ Edition; august 2010; Current Books International, Kolkata; Chapter -15; Pg no. 183-184.

10. VenkataRamanaVollala et at: High origin of an ulnar artery - Development and surgical significance; Chang gung Med J; Vol 34, No.6; July 2011.

\section{AUTHORS:}

1. K. P. S. Adinarayana

2. Teki Surekha

\section{PARTICULARS OF CONTRIBUTORS:}

1. I/C Professor, Department of Anatomy, Andhra Medical College, Visakhapatnam.

2. Final Year Post Graduate, Department of Anatomy, Andhra Medical College, Visakhapatnam.

\section{NAME ADDRESS EMAIL ID OF THE} CORRESPONDING AUTHOR:

Dr. Teki Surekha,

58-24-46/1,

Butchirajupalem,

Visakhapatnam-530027,

Andhra Pradesh.

E-mail: tekisurekha@gmail.com

Date of Submission: 09/01/2015.

Date of Peer Review: 10/01/2015.

Date of Acceptance: 22/01/2015.

Date of Publishing: 02/02/2015. 